\title{
The effects of probiotic and selenium co- supplementation on parameters of mental health, hormonal profiles, and biomarkers of inflammation and oxidative stress in women with polycystic ovary syndrome
}

\author{
Mehri Jamilian', Shirin Mansury ${ }^{1}$, Fereshteh Bahmani ${ }^{2}$, Zahra Heidar $^{3}$, Elaheh Amirani ${ }^{2}$ and Zatollah Asemi ${ }^{2 *}$
}

\begin{abstract}
Background: The aim of this study was to evaluate the effect of the co-administration of probiotic and selenium on parameters of mental health, hormonal profiles, and biomarkers of inflammation and oxidative stress in women with PCOS. Data on the effects of selenium and probiotic co-supplementation on mental health, hormonal and inflammatory parameters of patients with polycystic ovary syndrome (PCOS) are scarce. This investigation was carried out to evaluate the effects of selenium and probiotic co-supplementation on mental health, hormonal and inflammatory parameters in women with PCOS.
\end{abstract}

Methods: This randomized, double-blinded, placebo-controlled clinical trial was conducted on 60 subjects, aged 18-40 years old. Participants were randomly allocated into two groups to intake $8 \times 10^{9} \mathrm{CFU} /$ day probiotic plus $200 \mathrm{\mu g}$ /day selenium supplements $(n=30)$ or placebo $(n=30)$ for 12 weeks. Hormonal and inflammatory parameters were measured at baseline and after the 12-week intervention.

Results: Probiotic and selenium co-supplementation resulted in a significant improvement in beck depression inventory $(\beta-0.76 ; 95 \% \mathrm{Cl},-1.26,-0.26 ; P=0.003)$, general health questionnaire scores $(\beta-1.15 ; 95 \% \mathrm{Cl},-1.97$, $0.32 ; P=0.007)$ and depression anxiety and stress scale scores $(\beta-1.49 ; 95 \% \mathrm{Cl},-2.59,-0.39 ; P=0.009)$ compared with the placebo. Furthermore, probiotic and selenium co-supplementation significantly reduced total testosterone $(\beta-0.26 \mathrm{ng} / \mathrm{mL} ; 95 \% \mathrm{Cl},-0.51,-0.02 ; P=0.03)$, hirsutism $(\beta-0.43 ; 95 \% \mathrm{Cl},-0.74,-0.11 ; P=0.008)$, high-sensitivity C-reactive protein (hs-CRP) $(\beta-0.58 \mathrm{mg} / \mathrm{L} ; 95 \% \mathrm{Cl},-0.97,-0.19 ; P=0.004)$ and malondialdehyde (MDA) levels $(\beta-$ $0.29 \mu \mathrm{mol} / \mathrm{L} ; 95 \% \mathrm{Cl},-0.56,-0.02 ; \mathrm{P}=0.03)$, and significantly increased total antioxidant capacity (TAC) $(\beta+84$. $76 \mathrm{mmol} / \mathrm{L} ; 95 \% \mathrm{Cl},+48.08,+121.44 ; P<0.001)$ and total glutathione $(\mathrm{GSH})$ levels $(\beta+26.78 \mu \mathrm{mol} / \mathrm{L} ; 95 \% \mathrm{Cl},+4.33$, $+49.23 ; P=0.02)$ compared with the placebo.

Conclusions: Overall, the co-administration of probiotic and selenium for 12 weeks to women with PCOS had beneficial effects on mental health parameters, serum total testosterone, hirsutism, hs-CRP, TAC, GSH and MDA levels.

This study was prospectively registered in the Iranian website (www.irct.ir) for registration of clinical trials (http:// www.irct.ir: IRCT20170513033941N22).

Trial registration: IRCT20170513033941N22.

Keywords: Probiotic, Selenium, Mental health, Hormonal profiles, Inflammatory markers, Polycystic ovary syndrome

\footnotetext{
*Correspondence: asemi_r@yahoo.com

${ }^{2}$ Research Center for Biochemistry and Nutrition in Metabolic Diseases,

Kashan University of Medical Sciences, Kashan, I.R., Iran

Full list of author information is available at the end of the article
}

(c) The Author(s). 2018 Open Access This article is distributed under the terms of the Creative Commons Attribution 4.0 International License (http://creativecommons.org/licenses/by/4.0/), which permits unrestricted use, distribution, and reproduction in any medium, provided you give appropriate credit to the original author(s) and the source, provide a link to the Creative Commons license, and indicate if changes were made. The Creative Commons Public Domain Dedication waiver (http://creativecommons.org/publicdomain/zero/1.0/) applies to the data made available in this article, unless otherwise stated. 


\section{Background}

Polycystic ovary syndrome (PCOS) is an endocrine disturbances accompanied by a lot of conditions as well as economic burden [1]. Excess of androgens and related consequences including hirsutism and acne are notable clinical features of this disorder [2]. Prior evidence indicated that defected antioxidant defense and elevated inflammatory status contribute to the progression of PCOS [3, 4]. In addition, it has been stated that the gut microbiota dysbiosis is involved in the pathogenesis of PCOS $[5,6]$. A lower concentration of selenium is also reported in women with PCOS and a negative correlation is illustrated between selenium and testosterone levels [7]. In these patients, life style modification, as the first line of treatment, is associated with improvement in body composition, insulin resistance, hyperandrogenism and clinical manifestations [8].

Previous studies have shown several beneficial effects of probiotic supplementation on glycemic control in PCOS patients $[9,10]$. Moreover, some researchers have demonstrated that probiotic consumption in patients with osteoarthritis [11], type 2 diabetes mellitus (T2DM) [12], and gestational diabetes mellitus (GDM) [13] was associated with decreased inflammatory markers. On the other hand, selenium supplementation has been reported to improve antioxidant parameters in patients with metabolic syndrome [14]. In addition, in a study by Abedelahi et al. [15], it was seen that sodium selenite improved the in vitro follicular development by increasing total antioxidant capacity (TAC) levels. Selenium supplementation is thought to confer protective effects against oxidative stress and inflammation through reducing the formation of reactive oxygen species (ROS) and modulating of cellular signaling pathways [16]. Probiotic may affect antioxidant status and hormonal profiles by alleviating insulin resistance and anti-inflammatory properties [17, 18]. Recently, it is stated that probiotic plus selenium co-administration in animal models give better effects on metabolic responses and reproductive performance thorough additive actions [19, 20]. Combined probiotic and selenium supplementation may ameliorate clinical symptoms of patients with PCOS by improving their metabolic profiles and attenuating oxidative stress and inflammation. Therefore, we conducted this study to determine the effects of probiotic and selenium co-supplementation on parameters of mental health, hormonal profiles, and biomarkers of inflammation and oxidative stress in women with PCOS.

\section{Methods}

This randomized double-blinded, placebo-controlled trial registered in the Iranian website for registration of clinical trials (http://www.irct.ir: IRCT20170513033941N22) and followed the Declaration of Helsinki and Good Clinical
Practice guidelines. This trial was conducted among 60 women with PCOS, diagnosed based on the Rotterdam criteria [21], aged 18-40 years old whom referred to the Kosar Clinic in Arak, Iran, between December and March 2018. The study protocol was approved by the Ethics Committee of Arak University of Medical Sciences (AUMS). Written informed consent was obtained from all participants prior to the intervention. Exclusion criteria were as follows: pregnancy, adrenal hyperplasia, and rogen-secreting tumors, hyperprolactinemia, thyroid dysfunction, diabetes at enrollment.

\section{Supplementation}

Sixty PCOS women were randomized into two groups to intake either $8 \times 10^{9} \mathrm{CFU} /$ day probiotic containing Lactobacillus acidophilus, Lactobacillus reuteri, Lactobacillus fermentum and Bifidobacterium bifidum $(2 \times$ $10^{9} \mathrm{CFU} / \mathrm{g}$ each) plus $200 \mu \mathrm{g} /$ day selenium $(n=30)$ or placebo $(n=30)$ for 12 weeks. Shape and size of supplements and placebos capsules were similar and manufactured by Familact (Tehran, Iran) and Barij Essence Pharmaceuticals (Kashan, Iran), respectively. Compliance with probiotic and selenium supplements and the placebos was examined by asking subjects to return the medication containers and through brief daily cell phone reminders to take the supplements. All subjects completed 3-day diet recall at weeks $0,3,6,9$ and 12 of the intervention. Daily macro- and micro-nutrient intakes were calculated by nutritionist IV software (First Databank, San Bruno, CA).

\section{Assessment of outcomes}

Hormonal profiles were considered as the primary outcomes. Mental health parameters, biomarkers of inflammation and oxidative stress were recognized as the secondary outcomes.

\section{Clinical measures}

Mental health was judged with beck depression inventory (BDI), general health questionnaire-28 (GHQ-28) and depression anxiety and stress scale (DASS) at baseline and week 12 of the intervention. BDI is a self-compiled questionnaire of 21 items in multiple choice format [22]. The GHQ-28 comprises 28-item consisting of 4 subscales [23]. DASS questionnaire consists of three 14-item self-report scales that measure depression, anxiety and stress [24].

\section{Biochemical assessment}

Fasting blood samples $(15 \mathrm{ml})$ were collected at baseline and the end of the intervention at Arak reference laboratory. Serum total testosterone and sex hormone-binding globulin (SHBG) with inter- and intra-assay with interand intra-assay CVs of lower than 7\%\% were measured using commercial validated kits (DiaMetra, Milano, Italy). 
Free androgen index (FAI) was calculated as the percentage of total testosterone/SHBG. Serum high sensitivity C-reactive protein (hs-CRP) concentrations were quantified using commercial ELISA kit (LDN, Nordhorn, Germany) with inter- and intra-assay CVs of lower than $7 \%$. The plasma NO using Griess method [25], TAC concentrations using Benzie and Strain method [26], total glutathione (GSH) using Beutler method [27] and malondialdehyde (MDA) concentrations thiobarbituric acid reactive substances spectrophotometric test [28] were quantified with CVs less than $5 \%$.

\section{Statistical analyses}

The Kolmogorov-Smirnov test was done to determine the normality of data. Differences in dietary intakes between treatment groups were detected with independent-sample $t$-tests. Multiple linear regression models were used to assess the treatment effects on study outcomes after adjusting for confounding parameters including; age, and BMI. Significance of the treatment effects was presented as the mean differences with $95 \%$ confidence interval. Bootstrapping was also used as a sensitivity analysis of confidence interval. $P$-values $<0.05$ were considered statistically significant. All statistical analyses were done using the Statistical Package for Social Science version 18 (SPSS Inc., Chicago, Illinois, USA).

\section{Results}

As demonstrated in the study flow diagram (Fig. 1), during the enrollment phase of the study, there were 68 women with PCOS; however, 8 participants did not meet the inclusion criteria and thus were excluded. During the follow-up, 60 participants [placebo $(n=30)$ and probiotic and selenium co-supplementation $(n=30)]$ completed the trial.

Mean age, height, weight and BMI at baseline and after the 12-week intervention were not statistically different between the two groups (Table 1).

There was no statistically significant difference in terms of dietary macro- and micro-nutrient intakes between probiotic plus selenium, and placebo groups (Data not shown).

Probiotic and selenium co-supplementation resulted in a significant improvement in BDI ( $\beta-0.76 ; 95 \% \mathrm{CI},-1.26$, $0.26 ; P=0.003)$, GHQ $(\beta-1.15 ; 95 \% \mathrm{CI},-1.97,-0.32 ; P=$ $0.007)$ and DASS $(\beta-1.49 ; 95 \% \mathrm{CI},-2.59,-0.39 ; P=$ 0.009 ) compared with the placebo (Table 2). Furthermore, probiotic and selenium co-supplementation significantly reduced total testosterone $(\beta-0.26 \mathrm{ng} / \mathrm{mL} ; 95 \% \mathrm{CI},-0.51$, $0.02 ; P=0.03)$, hirsutism $(\beta-0.43 ; 95 \% \mathrm{CI},-0.74,-0.11$; $P=0.008)$, hs-CRP $(\beta-0.58 \mathrm{mg} / \mathrm{L} ; 95 \% \mathrm{CI},-0.97,-0.19$; $P=0.004)$ and $M D A$ levels $(\beta-0.29 \mu \mathrm{mol} / \mathrm{L} ; 95 \% \mathrm{CI},-$ $0.56,-0.02 ; \mathrm{P}=0.03)$, and significantly increased TAC $(\beta+$ $84.76 \mathrm{mmol} / \mathrm{L} ; 95 \% \mathrm{CI},+48.08,+121.44 ; P<0.001)$ and GSH levels $(\beta+26.78 \mu \mathrm{mol} / \mathrm{L} ; 95 \% \mathrm{CI},+4.33,+49.23 ; P=$ 0.02) compared with the placebo.

\section{Discussion}

In the present study, for the first time, we evaluated the effects of combined probiotic and selenium

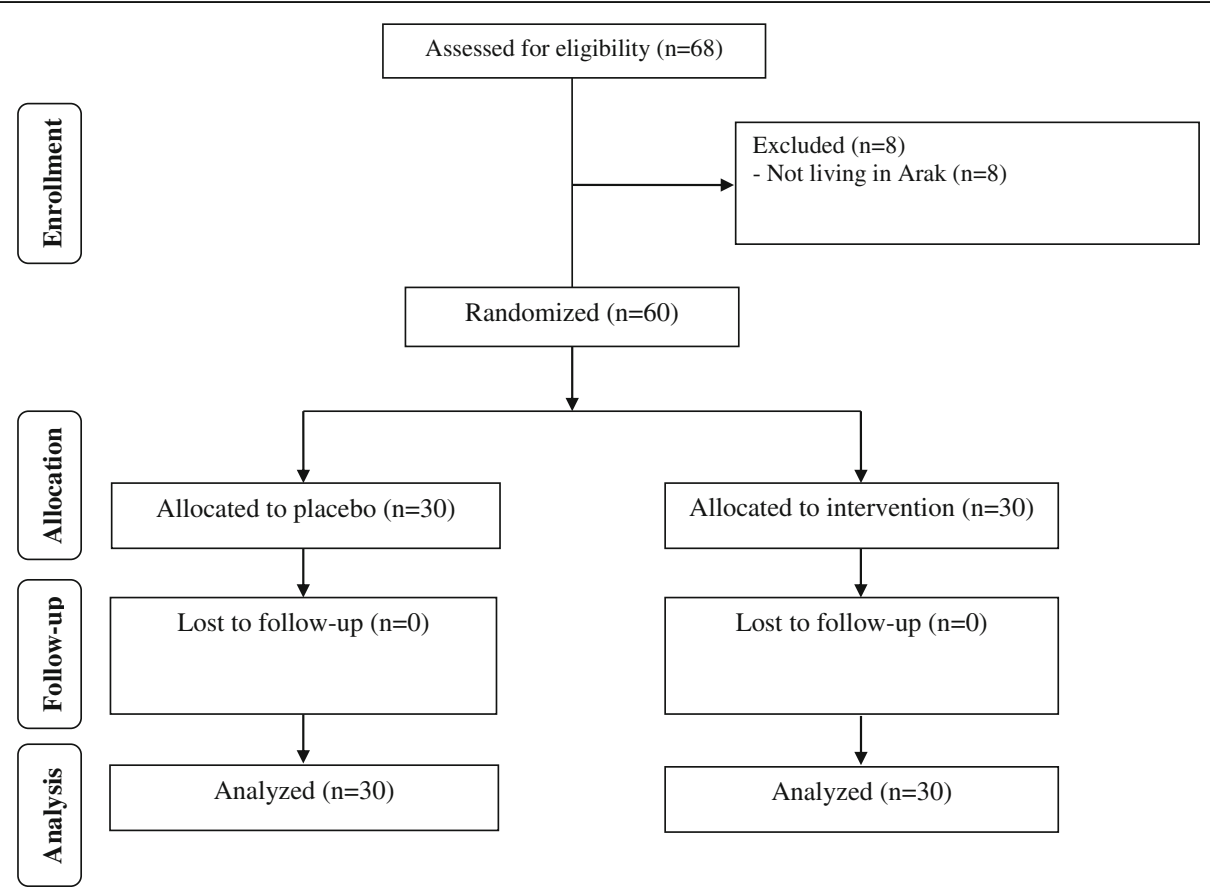

Fig. 1 Summary of patient flow diagram 
Table 1 General characteristics of study participants

\begin{tabular}{llll}
\hline & Placebo group $(n=30)$ & Probiotic plus selenium group $(n=30)$ & $P^{a}$ \\
\hline Age $(\mathrm{y})$ & $25.6 \pm 3.8$ & $26.0 \pm 5.3$ & 0.71 \\
Height $(\mathrm{cm})$ & $161.6 \pm 4.7$ & $161.0 \pm 4.4$ & 0.63 \\
Weight at study baseline $(\mathrm{kg})$ & $63.4 \pm 7.7$ & $63.9 \pm 9.3$ & 0.79 \\
Weight at end-of-trial $(\mathrm{kg})$ & $63.2 \pm 7.6$ & $63.5 \pm 9.2$ & 0.86 \\
Weight change $(\mathrm{kg})$ & $-0.2 \pm 0.7$ & $-0.4 \pm 0.5$ & 0.23 \\
BMl at study baseline $\left(\mathrm{kg} / \mathrm{m}^{2}\right)$ & $24.0 \pm 3.0$ & $24.6 \pm 3.3$ & 0.67 \\
BMl at end-of-trial $\left(\mathrm{kg} / \mathrm{m}^{2}\right)$ & $24.2 \pm 3.0$ & $24.5 \pm 3.3$ & 0.73 \\
BMl change $\left(\mathrm{kg} / \mathrm{m}^{2}\right)$ & $-0.1 \pm 0.3$ & $-0.2 \pm 0.2$ & 0.23 \\
\hline
\end{tabular}

Data are means \pm SDs

${ }^{\mathrm{a}}$ Obtained from independent-samples $t$-test

supplementation on hormonal responses, biomarkers of inflammation and oxidative stress in women with PCOS. We found that the co-administration of probiotic and selenium for 12 weeks to women with PCOS had beneficial effects on mental health parameters, serum total testosterone, hirsutism, hs-CRP, TAC, GSH and MDA levels.

\section{Effects on hormonal profiles}

Previous evidence showed that total- free testosterone, and other androgens are significantly increased in women with PCOS [29], which associate with further consequences including hirsutism, acne, and alopcia and predisposing to infertility in long term [30, 31]. Androgen excess also increases obesity, insulin resistance and blood pressure, which in turn contributes to developing cardiovascular disease [32]. In addition, it is stated that the reduction of testosterone levels improves endothelial dysfunction, body weight, and dyslipidemia and insulin sensitivity in these patients [33]. Our findings demonstrated that probiotic and selenium co-administration to women with PCOS decreased $\mathrm{mF}-\mathrm{G}$ scores and total testosterone, but did not affect SHBG concentrations. In addition, co-supplementation significantly improved mental health parameters. There are few studies investigating the effects of only probiotic or selenium supplementation on hormonal features of women with PCOS. In line with the present study, our previous research indicated that 12-week synbiotic supplementation decreased mF-G scores and increased SHBG levels in women with PCOS [34]. Moreover, probiotic supplementation for 12 weeks to women with PCOS led to a significant improvement in hirsutism, total testosterone and SHBG values [35]. In addition, it is reported that an

Table 2 Mental health and metabolic profiles at baseline and after the 12-week intervention in women with polycystic ovary syndrome that received either probiotic plus selenium supplements or placebo ${ }^{a}$

\begin{tabular}{|c|c|c|c|c|c|c|}
\hline \multirow[t]{2}{*}{ Variables } & \multicolumn{2}{|c|}{ Placebo group $(n=30)$} & \multicolumn{2}{|c|}{$\begin{array}{l}\text { Probiotic plus selenium group } \\
(n=30)\end{array}$} & \multicolumn{2}{|c|}{$\begin{array}{l}\text { Difference in outcome measures between probiotic plus } \\
\text { selenium and placebo groups }{ }^{a}\end{array}$} \\
\hline & Baseline & Week 12 & Baseline & Week 12 & $\beta(95 \% \mathrm{Cl})$ & $P^{b}$ \\
\hline BDI total scores & $15.6 \pm 4.4$ & $15.3 \pm 4.7$ & $15.5 \pm 4.0$ & $14.4 \pm 3.7$ & $-0.76(-1.26,-0.26)$ & 0.003 \\
\hline GHQ scores & $45.4 \pm 8.1$ & $44.6 \pm 8.2$ & $44.2 \pm 7.3$ & $42.4 \pm 6.7$ & $-1.15(-1.97,-0.32)$ & 0.007 \\
\hline DASS scores & $86.3 \pm 13.1$ & $85.1 \pm 12.9$ & $85.1 \pm 11.2$ & $82.5 \pm 10.9$ & $-1.49(-2.59,-0.39)$ & 0.009 \\
\hline Total testosterone (ng/mL) & $1.3 \pm 0.5$ & $1.3 \pm 0.4$ & $1.4 \pm 0.7$ & $1.1 \pm 0.6$ & $-0.26(-0.51,-0.02)$ & 0.03 \\
\hline SHBG (nmol/L) & $40.3 \pm 17.5$ & $40.4 \pm 18.3$ & $47.1 \pm 19.7$ & $49.5 \pm 22.1$ & $1.82(-1.77,5.42)$ & 0.31 \\
\hline mF-G scores & $13.0 \pm 3.7$ & $13.0 \pm 3.6$ & $14.5 \pm 3.2$ & $14.0 \pm 2.9$ & $-0.43(-0.74,-0.11)$ & 0.008 \\
\hline hs-CRP (mg/L) & $2.5 \pm 1.6$ & $2.7 \pm 1.5$ & $2.4 \pm 1.5$ & $2.0 \pm 1.5$ & $-0.58(-0.97,-0.19)$ & 0.004 \\
\hline $\mathrm{NO}(\mu \mathrm{mol} / \mathrm{L})$ & $36.5 \pm 3.8$ & $36.8 \pm 4.0$ & $36.6 \pm 2.3$ & $37.8 \pm 3.5$ & $0.94(-0.65,2.54)$ & 0.24 \\
\hline $\mathrm{TAC}(\mathrm{mmol} / \mathrm{L})$ & $909.9 \pm 110.8$ & $909.4 \pm 122.7$ & $933.3 \pm 59.8$ & $1012.9 \pm 69.4$ & $84.76(48.08,121.44)$ & $<0.001$ \\
\hline $\mathrm{GSH}(\mu \mathrm{mol} / \mathrm{L})$ & $496.4 \pm 88.1$ & $497.8 \pm 88.3$ & $528.3 \pm 88.3$ & $552.9 \pm 83.1$ & $26.78(4.33,49.23)$ & 0.02 \\
\hline MDA $(\mu \mathrm{mol} / \mathrm{L})$ & $2.4 \pm 0.5$ & $2.6 \pm 0.7$ & $2.8 \pm 0.2$ & $2.5 \pm 0.2$ & $-0.29(-0.56,-0.02)$ & 0.03 \\
\hline
\end{tabular}

Data are mean \pm SDs

a"Outcome measures" refers to the change in values of measures of interest between baseline and week 12. $\beta$ [difference in the mean outcomes measures between treatment groups (probiotic plus selenium group $=1$ and placebo group $=0$ )]

bobtained from multiple regression model (adjusted for baseline values of each biochemical variables, age and baseline BMI)

$B D I$ beck depression inventory, DASS depression anxiety and stress scale, GHQ general health questionnaire, GSH total glutathione, $h s$ - $C R P$ high-sensitivity C-

reactive protein, $m F-G$ modified Ferriman Gallwey, MDA malondialdehyde, NO nitric oxide, SHBG sex hormone-binding globulin, TAC total antioxidant capacity 
8-week selenium supplementation in women with PCOS decreased $\mathrm{mF}-\mathrm{G}$ scores, but did not affect free testosterone concentrations [36]. Although, selenium supplementation for 12 weeks did not affect total testosterone and SHBG levels in women with PCOS [37]. In contrast to our findings, probiotic supplementation to postmenopausal women did not enhance testosterone and SHBG levels [38]. The speculated mechanisms by which probiotic may improve hormonal profiles result from the balance of intestinal microbiota, enhancement of digestion and absorption of dietary nutrients [20], increasing insulin sensitivity [39], and interaction with the gut-brain axis [40]. In addition, induced oxidative stress involves in the development of hyperandrogenoism in PCOS [41]. The potential impacts of selenium supplementation on hormonal parameters may be explained by decreasing ROS production and elevating enzymatic anti oxidant activity [42].

\section{Effects on biomarkers of inflammation and oxidative stress}

Previous studies indicated that PCOS subjects are at risk for elevated inflammatory markers and abnormal antioxidant defense [43, 44]. In addition, it is demonstrated that in women with PCOS, inflammation involves in pancreatic beta cell dysfunction, insulin resistance, atherogenesis and ovarian disturbance [45], which accelerated by anti-oxidant imbalance [46]. The correction of oxidative stress and inflammatory status lead to alleviated hyperandrogenemia and atherogenic profiles [47, 48]. Our study indicated that probiotic and selenium co-supplementation to patients with PCOS resulted in a significant reduction in hs-CRP and MDA levels, and a significant increase in TAC and NO, but unchanged GSH concentrations. Similarly, selenium enriched probiotic in few animal studies enhanced antioxidant status. For instance, it is observed that a 4-week probiotic and selenium co-administration to mice fed a high-fat diet led to a significant decrease in MDA levels [19]. Similar results were observed in piglets grown in high ambient temperature after 6 weeks taking probiotic and selenium combination [49]. The findings of the present study are in agreement with our previous study indicated that a 10-week selenium supplementation to pregnant women at risk for intrauterine growth restriction resulted in decreased hs-CRP and elevated TAC levels [2]. Furthermore, an 8-week probiotic intervention in women with GDM significantly improved inflammation and oxidative stress biomarkers [50]. Although, Shoaei et al. [10] did not find any significant change in hs-CRP levels among women with PCOS receiving probiotic supplements for 8 weeks. In contrast to our study, 3-month selenium supplementation in patients with T2DM did not affect TAC levels [51]. Probiotic may attenuate inflammation and oxidative stress through metal ion chelating ability, modification of inflammatory signaling pathways, producing antioxidant metabolites, upregulating the antioxidant activity of the host and downregulating ROS producing enzymes [52]. Moreover, selenium involves in antioxidant defense system and play important roles in the increasing of glutathione peroxidase (GPx) activity, decreasing nuclear factor-kappaB (NF-kB) activation, inhibiting MAP kinase pathways and altering the metabolism of arachidonic acid, which in turn result in anti-inflammatory effects [53].

The current study had few limitations. Due to limited funding, we were unable to determine the effects of probiotic and selenium co-supplementation on circulating selenium levels. In the current study, sample size was low and did not meet our expectation. Future studies with longer duration of intervention, and large sample size are required to confirm the validity of our findings. The other limitation of this study was that the group of women surveyed was highly heterogeneous (1840 years). As we recruited patients with PCOS from a referral center, all patients were received similar treatments based on available guidelines. However, we believe that age range would not influence our findings because mean age was not significantly different between intervention and non-intervention groups. This should be taken into account in the interpretation of our findings.

\section{Conclusions}

Overall, the co-administration of probiotic and selenium for 12 weeks to women with PCOS had beneficial effects on mental health parameters, serum total testosterone, hirsutism, hs-CRP, TAC, GSH and MDA levels.

\section{Abbreviations}

BDI: Beck depression inventory; DASS: Depression anxiety and stress scale; GHQ: General health questionnaire; GSH: Total glutathione; hs-CRP: Highsensitivity C-reactive protein; MDA: Malondialdehyde; mF-G: modified Ferriman Gallwey; NO: nitric oxide; SHBG: sex hormone-binding globulin; TAC: total antioxidant capacity

\section{Acknowledgements \\ The present study was supported by a grant from the Vice-chancellor for Re- search, AUMS, Arak, and Iran. \\ Funding \\ The research grant provided by Research Deputy of Arak University of Medical Sciences (AUMS).}

\section{Availability of data and materials \\ The primary data for this study is available from the authors on direct request.}

\section{Authors' contributions}

ZA contributed in conception, design, statistical analysis and drafting of the manuscript. MJ, SM, FB, ZH and EA contributed in data collection and manuscript drafting. All authors approved the final version for submission. ZA supervised the study. 


\section{Ethics approval and consent to participate}

The study was conducted according to the ethical guidelines of the Declaration of Helsinki (the ethical standards of the institutional and national research committee and with the 1964 Helsinki declaration and its later amendments) and was approved by the ethics committee of the Arak University of Medical Sciences (AUMS), Arak, Iran (http://www.irctir: IRCT20170513033941N22). All participants provided a written informed consent.

\section{Consent for publication}

Not applicable.

\section{Competing interests}

The authors declare that they have no competing interests.

\section{Publisher's Note}

Springer Nature remains neutral with regard to jurisdictional claims in published maps and institutional affiliations.

\section{Author details}

${ }^{1}$ Department of Gynecology and Obstetrics, Endocrinology and Metabolism Research Center, School of Medicine, Arak University of Medical Sciences, Arak, Iran. ${ }^{2}$ Research Center for Biochemistry and Nutrition in Metabolic Diseases, Kashan University of Medical Sciences, Kashan, I.R., Iran. ${ }^{3}$ Infertility and Reproductive Health Research Center, Shahid Beheshti University of Medical Sciences, Tehran, Iran.

\section{Received: 10 June 2018 Accepted: 7 September 2018} Published online: 14 September 2018

\section{References}

1. Escobar-Morreale HF. Polycystic ovary syndrome: definition, aetiology, diagnosis and treatment. Nat Rev Endocrinol. 2018;14:270-84.

2. Mesdaghinia E, Rahavi A, Bahmani F, Sharifi N, Asemi Z. Clinical and metabolic response to selenium supplementation in pregnant women at risk for intrauterine growth restriction: randomized, double-blind, placebocontrolled trial. Biol Trace Elem Res. 2017;178:14-21.

3. Hyderali BN, Mala K. Oxidative stress and cardiovascular complications in polycystic ovarian syndrome. Eur J Obstet Gynecol Reprod Biol. 2015; 191:15-22.

4. Gonzalez F. Inflammation in polycystic ovary syndrome: underpinning of insulin resistance and ovarian dysfunction. Steroids. 2012;77:300-5.

5. Guo Y, Qi Y, Yang X, Zhao L, Wen S, Liu Y, et al. Association between polycystic ovary syndrome and gut microbiota. PLoS One. 2016;11: e0153196.

6. Liu R, Zhang C, Shi Y, Zhang F, Li L, Wang X, et al. Dysbiosis of gut microbiota associated with clinical parameters in polycystic ovary syndrome. Front Microbiol. 2017;8:324

7. Coskun A, Arikan T, Kilinc M, Arikan DC, Ekerbicer HC. Plasma selenium levels in Turkish women with polycystic ovary syndrome. Eur J Obstet Gynecol Reprod Biol. 2013;168:183-6.

8. Moran LJ, Hutchison SK, Norman RJ, Teede HJ. Lifestyle changes in women with polycystic ovary syndrome. Cochrane Database Syst Rev. 2011: CD007506. https://doi.org/10.1002/14651858.CD007506.pub2.

9. Ahmadi S, Jamilian M, Karamali M, Tajabadi-Ebrahimi M, Jafari P, Taghizadeh $M$, et al. Probiotic supplementation and the effects on weight loss, glycaemia and lipid profiles in women with polycystic ovary syndrome: a randomized, double-blind, placebo-controlled trial. Hum Fertil (Camb). 2017. 20:254-61.

10. Shoaei T, Heidari-Beni M, Tehrani HG, Feizi A, Esmaillzadeh A, Askari G. Effects of probiotic supplementation on pancreatic beta-cell function and c-reactive protein in women with polycystic ovary syndrome: a randomized double-blind placebo-controlled clinical trial. Int J Prev Med. 2015;6:27. https://doi.org/10.4103/2008-7802.153866.

11. Lei M, Guo C, Wang D, Zhang C, Hua L. The effect of probiotic Lactobacillus casei Shirota on knee osteoarthritis: a randomised double-blind, placebocontrolled clinical trial. Benef Microbes. 2017:8:697-703.

12. Mohamadshahi M, Veissi M, Haidari F, Shahbazian H, Kaydani GA, Mohammadi F. Effects of probiotic yogurt consumption on inflammatory biomarkers in patients with type 2 diabetes. Bioimpacts. 2014;4:83-8.
13. Jafarnejad S, Saremi S, Jafarnejad F, Arab A. Effects of a multispecies probiotic mixture on glycemic control and inflammatory status in women with gestational diabetes: a randomized controlled clinical trial. J Nutr Metab. 2016;2016:5190846.

14. Ju W, Li X, Li Z, Wu GR, Fu XF, Yang XM, et al. The effect of selenium supplementation on coronary heart disease: a systematic review and metaanalysis of randomized controlled trials. J Trace Elem Med Biol. 2017;44:8-16.

15. Abedelahi A, Salehnia M, Allameh AA, Davoodi D. Sodium selenite improves the in vitro follicular development by reducing the reactive oxygen species level and increasing the total antioxidant capacity and glutathione peroxide activity. Hum Reprod. 2010;25:977-85.

16. Mattmiller SA, Carlson BA, Sordillo LM. Regulation of inflammation by selenium and selenoproteins: impact on eicosanoid biosynthesis. J Nutr Sci. 2013;2:e28.

17. Ghoneim MA, Moselhy SS. Antioxidant status and hormonal profile reflected by experimental feeding of probiotics. Toxicol Ind Health. 2016:32:741-50.

18. Carvalho BM, Saad MJ. Influence of gut microbiota on subclinical inflammation and insulin resistance. Mediat Inflamm. 2013;2013:986734.

19. Nido SA, Shituleni SA, Mengistu BM, Liu Y, Khan AZ, Gan F, et al. Effects of selenium-enriched probiotics on lipid metabolism, Antioxidative status, histopathological lesions, and related gene expression in mice fed a highfat diet. Biol Trace Elem Res. 2016;171:399-409.

20. Pan C, Zhao Y, Liao SF, Chen F, Qin S, Wu X, et al. Effect of seleniumenriched probiotics on laying performance, egg quality, egg selenium content, and egg glutathione peroxidase activity. J Agric Food Chem. 2011; 59:11424-31.

21. Rotterdam ESHRE/ASRM-Sponsored PCOS Consensus Workshop Group. Revised 2003 consensus on diagnostic criteria and long-term health risks related to polycystic ovary syndrome. Fertil Steril. 2004;81:19-25.

22. Beck AT, Ward CH, Mendelson M, Mock J, Erbaugh J. An inventory for measuring depression. Arch Gen Psychiatry. 1961;4:561-71.

23. Goldberg DP, Hillier VF. A scaled version of the general health questionnaire. Psychol Med. 1979;9:139-45.

24. Crawford JR, Henry JD. The positive and negative affect schedule (PANAS): construct validity, measurement properties and normative data in a large non-clinical sample. Br J Clin Psychol. 2004:43:245-65.

25. Tatsch E, Bochi GV, Pereira Rda S, Kober H, Agertt VA, de Campos MM, et al. A simple and inexpensive automated technique for measurement of serum nitrite/nitrate. Clin Biochem. 2011;44:348-50.

26. Benzie IF, Strain JJ. The ferric reducing ability of plasma (FRAP) as a measure of "antioxidant power": the FRAP assay. Anal Biochem. 1996;239:70-6.

27. Beutler E, Gelbart T. Plasma glutathione in health and in patients with malignant disease. J Lab Clin Med. 1985;105:581-4.

28. Janero DR. Malondialdehyde and thiobarbituric acid-reactivity as diagnostic indices of lipid peroxidation and peroxidative tissue injury. Free Radic Biol Med. 1990;9:515-40.

29. Huang A, Brennan K, Azziz R. Prevalence of hyperandrogenemia in the polycystic ovary syndrome diagnosed by the National Institutes of Health 1990 criteria. Fertil Steril. 2010:93:1938-41.

30. Wehr E, Moller R, Horejsi R, Giuliani A, Kopera D, Schweighofer N, et al. Subcutaneous adipose tissue topography and metabolic disturbances in polycystic ovary syndrome. Wien Klin Wochenschr. 2009;121:262-9.

31. West S, Lashen H, Bloigu A, Franks S, Puukka K, Ruokonen A, et al. Irregular menstruation and hyperandrogenaemia in adolescence are associated with polycystic ovary syndrome and infertility in later life: northern Finland birth cohort 1986 study. Hum Reprod. 2014;29:2339-51.

32. Yanes Cardozo LL, Romero DG, Reckelhoff JF. Cardiometabolic features of polycystic ovary syndrome: role of androgens. Physiology (Bethesda). 2017; 32:357-66.

33. Amiri M, Golsorkhtabaramiri M, Esmaeilzadeh S, Ghofrani F, Bijani A, Ghorbani $L$, et al. Effect of metformin and flutamide on anthropometric indices and laboratory tests in obese/overweight PCOS women under hypocaloric diet. J Reprod Infertil. 2014;15:205-13.

34. Nasri K, Jamilian M, Rahmani E, Bahmani F, Tajabadi-Ebrahimi M, Asemi Z The effects of synbiotic supplementation on hormonal status, biomarkers of inflammation and oxidative stress in subjects with polycystic ovary syndrome: a randomized, double-blind, placebo-controlled trial. BMC Endocr Disord. 2018;18:21.

35. Karamali M, Eghbalpour S, Rajabi S, Jamilian M, Bahmani F, TajabadiEbrahimi $\mathrm{M}$, et al. Effects of probiotic supplementation on hormonal profiles, biomarkers of inflammation and oxidative stress in women with 
polycystic ovary syndrome: a randomized, double-blind, placebo-controlled trial. Arch Iran Med. 2018;21:1-7.

36. Razavi M, Jamilian M, Kashan ZF, Heidar Z, Mohseni M, Ghandi Y, et al. Selenium supplementation and the effects on reproductive outcomes, biomarkers of inflammation, and oxidative stress in women with polycystic ovary syndrome. Horm Metab Res. 2016;48:185-90.

37. Mohammad Hosseinzadeh F, Hosseinzadeh-Attar MJ, Yekaninejad MS, Rashidi B. Effects of selenium supplementation on glucose homeostasis and free androgen index in women with polycystic ovary syndrome: a randomized, double blinded, placebo controlled clinical trial. J Trace Elem Med Biol. 2016;34:56-61.

38. Nettleton JA, Greany KA, Thomas W, Wangen KE, Adlercreutz H, Kurzer MS Short-term soy and probiotic supplementation does not markedly affect concentrations of reproductive hormones in postmenopausal women with and without histories of breast cancer. J Altern Complement Med. 2005;11: 1067-74.

39. Crommen S, Simon MC. Microbial regulation of glucose metabolism and insulin resistance. Genes. 2017;9. https://doi.org/10.3390/genes9010010.

40. Saydam BO, Yildiz BO. Gut-brain axis and metabolism in polycystic ovary syndrome. Curr Pharm Des. 2016;22:5572-87.

41. Gonzalez F, Sia CL, Shepard MK, Rote NS, Minium J. Hyperglycemiainduced oxidative stress is independent of excess abdominal adiposity in normal-weight women with polycystic ovary syndrome. Hum Reprod. 2012;27:3560-8

42. Wang S, He G, Chen M, Zuo T, Xu W, Liu X. The role of antioxidant enzymes in the ovaries. Oxidative Med Cell Longev. 2017:2017:4371714.

43. Murri M, Luque-Ramirez M, Insenser M, Ojeda-Ojeda M, Escobar-Morreale HF. Circulating markers of oxidative stress and polycystic ovary syndrome (PCOS): a systematic review and meta-analysis. Hum Reprod Update. 2013; 19:268-88.

44. Escobar-Morreale HF, Luque-Ramirez M, Gonzalez F. Circulating inflammatory markers in polycystic ovary syndrome: a systematic review and metaanalysis. Fertil Steril. 2011;95:1048-58.e1-2.

45. Gonzalez F. Nutrient-induced inflammation in polycystic ovary syndrome: role in the development of metabolic aberration and ovarian dysfunction. Semin Reprod Med. 2015;33:276-86.

46. Zuo T, Zhu M, Xu W. Roles of oxidative stress in polycystic ovary syndrome and cancers. Oxidative Med Cell Longev. 2016;2016:8589318.

47. Sathyapalan T, Shepherd J, Coady AM, Kilpatrick ES, Atkin SL. Atorvastatin reduces malondialdehyde concentrations in patients with polycystic ovary syndrome. J Clin Endocrinol Metab. 2012;97:3951-5.

48. Diamanti-Kandarakis E, Paterakis T, Alexandraki K, Piperi C, Aessopos A, Katsikis I, et al. Indices of low-grade chronic inflammation in polycystic ovary syndrome and the beneficial effect of metformin. Hum Reprod. 2006; 21:1426-31.

49. Gan F, Chen X, Liao SF, Lv C, Ren F, Ye G, et al. Selenium-enriched probiotics improve antioxidant status, immune function, and selenoprotein gene expression of piglets raised under high ambient temperature. J Agric Food Chem. 2014;62:4502-8.

50. Hajifaraji M, Jahanjou F, Abbasalizadeh F, Aghamohammadzadeh N, Abbasi MM, Dolatkhah N. Effect of probiotic supplements in women with gestational diabetes mellitus on inflammation and oxidative stress biomarkers: a randomized clinical trial. Asia Pac J Clin Nutr. 2018;27:581-91.

51. Faghihi T, Radfar M, Barmal M, Amini P, Qorbani M, Abdollahi M, et al. A randomized, placebo-controlled trial of selenium supplementation in patients with type 2 diabetes: effects on glucose homeostasis, oxidative stress, and lipid profile. Am J Ther. 2014;21:491-5.

52. Wang $Y$, Wu Y, Wang $Y, X u H$, Mei X, Yu D, et al. Antioxidant properties of probiotic bacteria. Nutrients. 2017;9. https://doi.org/10.3390/nu9050521.

53. Duntas LH. Selenium and inflammation: underlying anti-inflammatory mechanisms. Horm Metab Res. 2009:41:443-7.

Ready to submit your research? Choose BMC and benefit from:
- fast, convenient online submission
- thorough peer review by experienced researchers in your field
- rapid publication on acceptance
- support for research data, including large and complex data types
- gold Open Access which fosters wider collaboration and increased citations
- maximum visibility for your research: over 100M website views per year
At BMC, research is always in progress.
Learn more biomedcentral.com/submissions

